\title{
Using the cloud to provide telemedicine services in a developing country
}

Author:
Liezel Cilliers ${ }^{1}$
Affiliation:
IInformation Systems
Department, University of
Fort Hare, South Africa
Correspondence to:
Liezel Cilliers
Email:
Icilliers@ufh.ac.za
Postal address:
50 Church Street, East
London 5201, South Africa
Dates:
Received: 06 Feb. 2014
Accepted: 26 July 2014
Published: 18 Nov. 2014
How to cite this article:
Cilliers, L., 2014, 'Using
the cloud to provide
telemedicine services in
a developing country', SA
Journal of Information
Management 16(1), Art.
\#611, 7 pages. http://dx.doi.
org/10.4102/sajim.v16i1.611
Co 2014. The Authors.
Licensee: AOSIS
ipenJournals. This work
Attibution License.

Attribution License.
Background: According to the World Health Organisation (WHO) 'Telemedicine is the use of medical information exchanged from one site to another via communications to improve a patient's health'. Despite the documented advantages of telemedicine, especially in developing countries, the implementation of this technology has been slow, with most projects not succeeding past the pilot phase.

Objectives: The aim of the article is to provide critical success factors (CSF) that will enable the deployment of telemedicine in the cloud in order to improve health care services in developing countries.

Methods: A thorough literature review was performed of peer reviewed articles in order to identify possible barriers for telemedicine to be deployed in the cloud. Furthermore, the Technology Organization Environmental Model was used in order to group the barriers according to the various factors and, from this process, critical success factors were formulated for consideration.

Conclusion: Five critical success factors were formulated in order to implement telemedicine making use of the cloud in developing countries. These include having a national integrated plan for telemedicine; promoting best practices within a legislation framework; involving the end user; providing education to improve levels of telemedicine awareness amongst staff and patients, and addressing technological issues.

\section{Introduction}

The average doctor to patient ratio in South Africa is estimated to be 1:1300, whilst in some rural areas this ratio can reach up to 1:100 000 (IRIN 2008; Jacobs 2007). The accessibility and quality of health care services in rural and urban areas can be improved by making use of Information and Communication Technologies (ICT). In particular health information systems, and especially telemedicine, have been identified by the World Health Organisation (WHO) as possible tools in this process (Fichman et al. 2011; WHO 2011). Telemedicine provides access to specialised health care in rural areas (WHO 2011). This means that patients need not travel far, to urban hospitals, for treatment by a specialist, thus, this reduces waiting times and transportation costs. In addition, health care workers in the rural areas also benefit from telemedicine as they receive support and education from their urban colleagues (WHO 2011; Wootton et al. 2009).

Despite the advantages mentioned in the previous paragraph, the uptake of telemedicine in South Africa has been slow (Van Dyk, Fortuin \& Schutte 2012). Motsoaledi (2010) reported that only $34 \%$ of existing telemedicine sites in South Africa were operational. Some of the reasons provided for this poor result include the unreliable electricity supply which results in the unreliability of the technology, poor connectivity and low Internet bandwidth (Mars 2012; Jack \& Mars 2008).

Other factors that have been reported in literature include a lack of sustainable finance to implement telemedicine infrastructure, and also a lack of skill to maintain the technology (Cilliers \& Flowerday 2013). The aim of this article is to investigate cloud computing as a possible solution to some of the technological problems mentioned above. In order to accomplish this goal, a thorough literature search was conducted on the most popular academic databases: Pubmed, EBSCO, ProQuest and JSTOR. The purpose of the search was to identify relevant high quality studies that documented the barriers to the implementation of telemedicine in developing countries. For this reason, databases that were likely to yield original research in this area were targeted.

The rest of the article is structured as follows: The next section provides an overview of cloud computing, including the advantages, services provided and different deployment types available. This is followed by the barriers that have been reported to the successful implementation of 
cloud computing in various fields, whilst the section after that provides examples of various types of telemedicine projects that have been introduced in health care. From this the barriers are integrated with the Technology Organization Environmental (TOE) Framework with specific reference to telemedicine. Finally, the last section will identify and discuss the critical success factors (CSF) that must be considered if cloud computing is used to provide telemedicine services.

\section{Cloud computing}

Ragent and Leach (2010) define cloud computing as '...an Internet based computing model which enables convenient, on-demand network access to shared resources, software and information which is provided to computers and other devices.'

The main advantage of cloud computing is that it increases productivity and decreases the cost of Information Technology (IT), which was expensive prior to the invention of the cloud (ISACA 2009). Koch and Brakel (2012) identified various key benefits about why health organisations should make use of the cloud instead of traditional Information and Communication Technologies (ICTs). Some of these benefits of the cloud are listed below (Koch \& Brakel 2012):

1. It reduces IT costs. Health care organisations can reduce the cost of IT infrastructure investments and on-going maintenance expenditures by paying only for the services they need.

2. It reduces implementation risks. Cloud computing can be deployed rapidly as the purchasing of hardware, licenses and software is not needed.

3. Flexibility is increased. The cloud provides more flexibility in the response and speed of health staff as they can access information and applications at any time, and from anywhere.

4. Health staff are enabled to focus on core areas - health staff can focus on patient care as the technology is maintained and provided by a third-party.

5. It improves scalability. Health care organisations only pay for the telemedicine services that they need. For telemedicine that could mean bandwidth, tailored telemedicine software programs or storage space.

The next section will introduce the various cloud computing services that are on offer.

\section{Types of cloud computing services offered}

Cloud computing can provide various types of services. The three main types of services are illustrated in Figure 1 and briefly discussed below.

- Software as a Service (SaaS): Amrhein and Anderson (2009) define SaaS as a model in which 'the consumer uses an application, but does not control the operating system, hardware or network infrastructure on which it is running'.
- Platform as a Service (PaaS): In this model 'the consumer does not manage or control the underlying cloud infrastructure, network, servers, operating systems, or storage; but the consumer has control over the deployed applications and possibly the application hosting environment configurations' (Baize 2011).

- Infrastructure as a Service (IaaS): The IaaS model of cloud computing offers the user the capability to rent computing, storage, networks and other computing resources with the added capability 'to deploy and run arbitrary software, which can include operating systems and applications' (Baize 2011).

The SaaS service will be more beneficial to departments with little skill or capacity, whilst more mature departments may prefer the PaaS or IaaS service structures. The next section will investigate the deployment models associated with cloud computing.

\section{Deployment models of the cloud}

According to Cisco (2009), a cloud deployment model defines where the physical servers are deployed and who manages them. There are four recognised deployment models that are used in cloud computing: Private, Community, Public, and Hybrid clouds.

The public cloud is also referred to as the external cloud where the 'infrastructure is made available to the general public' through web browsers, but offers limited customer control (Truong et al. 2012). In contrast, the private cloud systems emulate public cloud service offerings within an organisation's boundaries to make services accessible for one designated organisation. Private cloud computing systems make use of virtualisation solutions and focus on consolidating distributed IT services often within data centres belonging to the company (Gonçalves \& Ballon 2011). The community cloud infrastructure is shared by numerous organisations. The community cloud is a more expensive option as compared to the public cloud, as the operational costs are spread over fewer user organisations than the public cloud. However, this type of cloud provides the benefit of

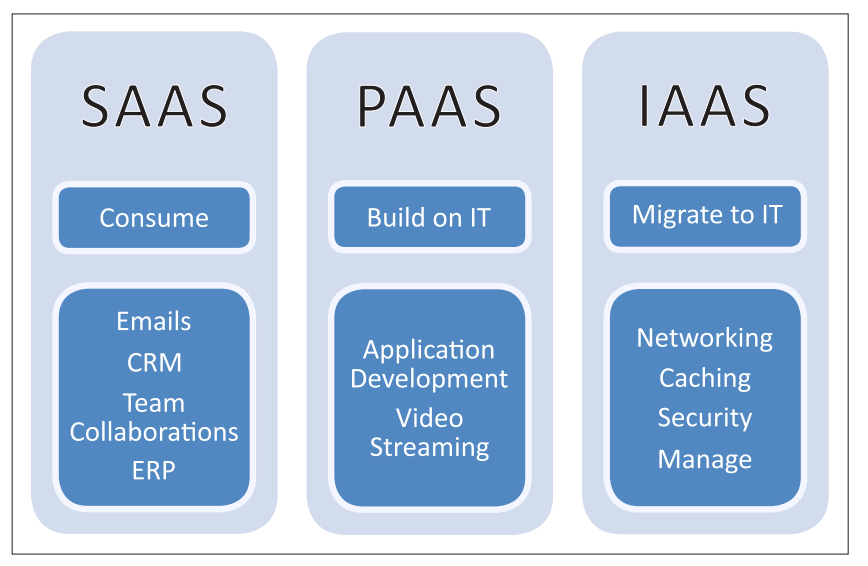

Source: Amrhein, D. \& Anderson, P., 2009, 'Cloud computing use cases white paper: Version $2.0^{\prime}$, viewed 04 September 2014, from http://www.cloudusecases.org/Cloud_Computing Use_Cases_Whitepaper-4_0.odt

FIGURE 1: Types of Services offered by cloud computing. 
offering a higher level of privacy, security and compliance. This is the type of cloud computing in which organisations are compelled to invest more trust, and adopt because of its safety features, especially for organisations that deal with critical or fragile information (Baize 2011). The last cloud computing type is called the Hybrid cloud and:

is a composition of two or more clouds (private, community or public) that remains unique entities, but is bound together by standardised or proprietary technology that enables data and application portability. (Baize 2011)

In order to integrate telemedicine beyond the borders of South Africa, a community cloud may be considered. Alternatively, a public or private cloud type can be used according to the budget and security considerations of the particular telemedicine project.

\section{Barriers to cloud computing}

A study conducted by Boss et al. (2007) notes that with any new technology there are potential barriers that can be expected. According to Low, Chen and Wu (2011), a barrier is defined as a substance or obstacle which prevents a human being from attaining a particular goal. The barriers listed below are adopted from a literature study conducted by Duhaime (2011).

According to Schwab (2010), fear of vendor lock-in is a situation whereby a person using the cloud services cannot easily change to other technologies. Reliability concerns are one of the main reasons new users are reluctant to trust third-party cloud providers to store or process sensitive or personal information (Comninos 2011). This is especially important in the health context where patient data will be transmitted and stored by making use of telemedicine.

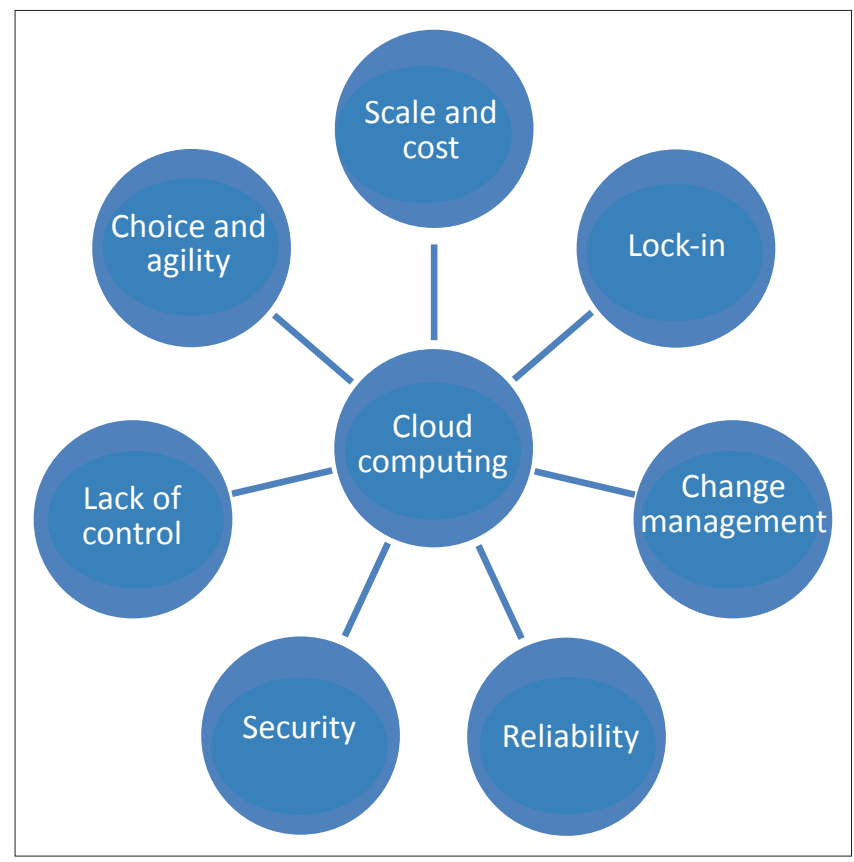

Source: Adapted from Duhaime, D., 2011, 'The pros and cons of cloud computing', ExpectFocus ${ }^{\oplus} 111$, Summer.

FIGURE 2: Generic barriers to the implementation of cloud computing.
Comninos (2011) further posits that reliability issues are closely related to connectivity issues, because the features of cloud computing makes use of the Internet as the main transporting device. This was previously also a concern for health providers, but with the increased network coverage in South Africa, it has now been addressed (Jack \& Mars 2008). Performance concern is an additional challenge concerning cloud adoption in health care settings. The performance concerns of cloud computing for telemedicine are wideranging and include the availability of cloud related services in South Africa, awareness of the cloud, dispersal of the cloud, and the width and depth of cloud adoption (Malhotra 2010). Malhotra (2010) mentions some of the key challenges for performance improvement. These include the following:

- storage services

- scaling

- network services

- scheduling

- service level agreement templates

- optimal location of data centres and software components

- efficient SQL query processing

- architecture and process improvement.

Cloud computing is seen as inherently insecure. This is because security in the cloud is often intangible and less visible than many other forms of computing, and contributes to the perceived lack of control on the users' part. Despite these challenges, there are examples of successful telemedicine deployment in both developed and developing countries. The next section will provide a discussion about such examples.

\section{Telemedicine and the cloud}

Telemedicine in the cloud is not confined to providing health care service, but can also be developed for specific instruments. This section provides an overview of a variety of these projects both in developed and developing countries:

- In Brazil a proposal was developed by the Federal University of Santa Catarina to employ wireless sensor networks which are used to monitor patients. The information obtained is made available in the cloud to medical staff and can be processed by relevant expert systems whilst stored there (Rolim et al. 2010).

- Melvin and Pranesh (2013) have designed an Immediate Medical Care Unit (IMCU) that is able to provide basic health care services to the rural areas in India. The IMCU is an interactive machine that collects data from the patient, such as blood tests and blood pressure readings. It also integrates this information with the existing patient's record, making continuous care possible. In order to perform these activities cloud computing is used to interconnect the different databases.

- Germany has introduced a health smart card for all insured patients. The smart card contains administrative information, electronic health records and medical data such as prescriptions and emergency information. A smart card can be used by patients who must consult with different health professionals in order to keep their 
medical information up to date. This would be useful in telemedicine as both the treating and referring health professionals will have access to this information via the cloud (Lohr, Sadeghi \& Winandy 2010). In order to do this the information must be stored in the cloud. Whilst the International Organisation for Standardization has provided security and privacy guidelines for this process, the current challenge is the interoperability of the various systems that do exist (ISO 2013).

- Hsieh and Hsu (2012) developed a cloud computing based telemedicine application which makes use of a 12-lead ECG telemedicine service that greatly improved the current accuracy of reports in telecardiology. The readings can be viewed on both mobile and fixed devices connected to the cloud network, and have been reported to be convenient, efficient and inexpensive for clinicians in rural areas to use.

- Cloud computing enables researchers from different countries to collaborate as vast amounts of information can be stored and made available in this environment. The information can be analysed by researchers to provide guidelines for better decision-making, and new developments in treatment and medicine (Arphitha 2013).

- The Picture Archiving and Communication System (PACS), used for medical images in many hospitals, is experiencing scalability and maintenance issues resulting from the high volume of images that are taken daily. Cloud computing is considered to be a possible solution to this problem as images can be stored at lower cost, it provides high scalability and availability of images, and is recoverable in a disaster situation. Cloud computing can also be used in telemedicine as it provides the same advantages with the added benefit of specialist reporting in a short time period for the patient. This can be crucial in an emergency situation in the rural areas where no radiologist is available (Teng et al. 2010).

The next section will discuss the TOE framework as it relates to telemedicine and the cloud.

\section{Technology Organization Environment framework}

The TOE framework has been chosen for this research study because of its use in an analytical framework that is appropriate for studying the adoption and assimilation of different types of IT innovation. The framework was developed from a theoretical basis and is supported by consistent empirical evidence (Oliveira \& Martins 2011). The TOE framework makes use of technological, environmental and organisational contexts for implementing cloud computing, to deploy telemedicine services in a developing country. The barriers that have been identified in the previous section are now considered in relation to telemedicine and are aligned accordingly into the three different contexts of the TOE framework.

\section{Technology}

Telemedicine initiatives in Africa are often announced with much excitement, but few survive beyond the pilot phase
(Mars 2013). Telemedicine has become an integral part of the Department of Health's E-health plan in South Africa, but this means that the ICT infrastructure must be in place to support telemedicine. One of the inhibitors to telemedicine in rural areas is a stable electricity supply and the high cost of connectivity in South Africa. In addition, ICT must be maintained and supported by qualified staff (Mars 2013).

Reliability of cloud technology is important as it will be used in the health care domain. If connectivity and bandwidth are a problem, the asynchronous mode of telemedicine can be used, whereby a message is sent to a specialist to review an issue at a later stage or at their convenience. For this approach all that is needed is a basic computer with Internet connectivity and a camera (Singh 2009).

The cost of making use of cloud computing can be a concern as the technology must be integrated into existing IT infrastructure. However, once this has been implemented, the cost of maintaining the cloud is not a concern for the user. Similarly, the user only pays for the telemedicine services he or she requires and, thereby, saves money (Duhaime 2011).

\section{Organisation}

One of the factors that have been identified as a possible obstacle for the successful implementation of telemedicine is user acceptance (Nwabueze et al. 2009). Change management, and making use of communication and education is, therefore, necessary to reduce the resistance to the introduction of telemedicine in the initial stages of implementation (Cilliers \& Flowerday 2013). This is equally important when cloud computing is used to deploy telemedicine services, as privacy concerns and a lack of control can contribute to the low acceptance rate of the technology.

Users of the cloud often mention that they perceive themselves to have less control over the services that the cloud offers, and the measures in place to protect their information than over other services. Mauch, Kunze, and Hillenbrand (2012) state that multi-tenancy is a key element to cloud computing and, thus, a 'one size fits all' approach is not suitable. They further acknowledge that architecture must be designed in such a way to allow for customisation for a specific user according to their needs, otherwise telemedicine will simply add steps to the clinical workflow and increase the workload of already overburdened health staff (Mars 2013).

\section{Environment}

The South African Minister of Health, Dr. Motsoaledi (2010), suggested that legislation regarding telemedicine must be prioritised in future. In response, The Health Professions Council of South Africa has worked on the 'Guidelines for the Practice of Telemedicine' for the past seven years. Criticism of their definition of telemedicine is that it is too broad and it omits the important keywords: 'information', 'communication' and 'technology' (Mars 2013). 
Issues such as liability, accountability, licensure, jurisdiction, confidentiality, data security and the use of telemedicine in health technology across borders must be addressed as a matter of urgency. This is important as the patient is not in a face-to-face contact situation with the health care worker treating them, and they may never have any communication with the specialist responsible for the diagnosis or treatment plan (Cilliers \& Flowerday 2010). Accepted practices include that the specialist provides a second opinion whilst the referring doctor will remain responsible for the patient. Where telemedicine is practiced across borders, this raises the question of licensure for the specialist (Motsoaledi 2010).

Similarly, there are privacy and security concerns surrounding cloud computing. Rosado et al. (2012) state that because cloud computing is a relatively new computing model, there are concerns about security at all levels (e.g. network, host, application and data levels). There are new challenges arising in cloud computing, some of which are principally exacerbated by the cloud models. Thus, the risk is directly dependent on the cloud service and cloud deployment model (Mauch et al. 2012).

Madhavaiah, Bashir and Shafi (2012) identify that cloud computing, as an emerging IT model, has only had an arguably short period to be developed into a fully formed paradigm. The availability and, therefore, choice and agility, of the technology remains limited. In the next section the CSFs that will address the identified problems will be discussed.

\section{Critical success factors}

In the previous section the barriers for making use of the cloud to provide telemedicine services in developing countries were discussed and aligned to the TOE framework. In summary, the following critical areas were identified:

- technology: vendor lock-in; reliability; scale and cost

- organisation: change management; lack of control

- environment: security; accountability, licensure and agility.

CSFs are defined as the critical areas in which an organisation or the individual must succeed, in order to achieve their mission. CSFs also involve examining and categorising the impact of those critical areas (Salaheldin 2009). The following five CSFs are used to address the critical areas that will allow telemedicine services to be deployed, by making use of cloud computing in developing countries.

\section{CSF 1: National integrated plan for telemedicine}

Telemedicine has become an integral part of the Department of Health's E-health plan in South Africa and the Department must take responsibility for the implementation of telemedicine. If the Department of Health provides a national integrated plan for the implementation of telemedicine in all provinces, it will address the problem of vendor lock-in as the entire system must make use of one system. The telemedicine system will also be integrated across all provinces, making the coordination of health services in the country much easier. If the cloud is used as the deployment strategy for telemedicine services in the country, it will also limit cost as the Department of Health will only pay for the service and not infrastructure or IT maintenance. With the use of a national integrated plan, security concerns are also addressed as the minimum security standards will be provided for the entire system.

\section{CSF 2: Best practices within a legislation framework}

With the advent of telemedicine, the provision of health care services has changed. Health care can now be provided across borders and without the patient ever knowing who is responsible for their diagnoses. This raises privacy and ethical concerns that must be addressed within a legal framework. If a proper legal framework is in place, it will also provide for more control than at present for the user, as they are aware of their rights and responsibilities within the system. The security concerns within cloud computing must also be addressed via legislation. These concerns are especially important where patient information is transmitted or stored making use of the cloud as it raises serious privacy concerns if the information was to be breached.

\section{CSF 3: Involve the end user}

The end user refers to both the health care worker and patient. This factor speaks to the change management problem that was identified in the previous section. If the end user is aware of the technology, legislation and best practices surrounding making use of the cloud to provide telemedicine services, there will be less resistance than might otherwise occur. This is especially important in a developing country where computer literacy and awareness of technology is low. This factor also links to CSF 4.

\section{CSF 4: Provide education to improve levels of awareness}

The end users, both patients and health care workers, must be educated about the advantages and potential risks of telemedicine and cloud computing. With this knowledge, it will increase the user acceptance of the technology.

\section{CSF 5: Address technology issues}

Cloud computing continues to be a relatively new paradigm with many challenges. Despite this, if attention is given to the specific technology problems within the context of telemedicine, it will not only increase the utilisation of telemedicine in the cloud, but also contribute to the wider context of cloud computing. Specific technology factors that must be introduced include the reliability, cost and availability of the technology. These are important as telemedicine services must be consistently reliable if they are to be of any use. The cost of deploying telemedicine services that make use of the cloud will decrease as more deployment options become available. The cost of bandwidth, which is very expensive in South Africa, must also be decreased in order to make this a viable technology. In developing countries, especially where IT infrastructure is poorly developed, cloud computing makes use of existing Internet connections to deploy telemedicine, without requiring more infrastructure or financial investments than are already in place. 
TABLE 1: Critical success factors (CSFs) and the Technology Organization Environmental (TOE) framework.

Critical success factors
CSF 1: National integrated plan for telemedicine
CSF 2: Best practices within a legislation framework
CSF 3: Involve the end user
CSF 4: Provide education to improve levels of awareness
CSF 5: Address technology issues

The CSFs presented in this section attempt to address the barriers that were identified by Duhaime (2011) to make use of cloud computing in order to deploy telemedicine services in South Africa. Table 1 shows how the CSFs can be mapped to the three contexts of the TOE framework.

\section{Conclusion}

This article provided CSFs that must be considered when deploying telemedicine services in a developing country making use of cloud computing. The benefits of telemedicine have been documented in literature, but despite this, only a third of the telemedicine sites in South Africa are functional. In order to address some of the problems that have been cited as the reason for this poor result, cloud computing was introduced as a possible solution. Telemedicine services can be hosted in the cloud and the Department of Health can buy only those services that are needed. This is cost effective as the infrastructure and maintenance cost is deferred to a third party. The barriers that can prevent this technology being used to deploy telemedicine services were identified and CSFs were formulated to address these. Future research should focus on how each of these CSFs influence the implementation of telemedicine in more detail than is presently available. In addition, there is currently no effective measure to determine the cost of investment in telemedicine as it is very difficult to measure the impact the technology has on the health environment. This prohibits further investment and infrastructure development.

\section{Acknowledgements Competing interests}

The author declares that she has no financial or personal relationship(s) that may have inappropriately influenced her in writing this article.

\section{References}

Amrhein, D. \& Anderson, P., 2009, 'Cloud computing use cases white paper: Version 2.0', viewed 04 September 2014, from http://www.cloudusecases.org/Cloud Computing Use Cases Whitepaper-4_0.odt

Arphitha, S., 2013, 'Cloud computing: A boon to healthcare', Policy 6, 12-15.

Baize, B., 2011, 'In Cloud We Trust', Cloud Computing 16, 21-30.

Boss, G., Malladi, P., Quan, D., Legregni, L. \& Hall, H., 2007, Cloud computing, IBM White Paper, Armonk.

Cilliers, L. \& Flowerday, S., 2010, Critical success factors for Telemedicine Centres in African countries, University of Fort Hare, Alice.

Cilliers, L. \& Flowerday, S., 2013, 'Health information systems to improve health care: A telemedicine case study', SA Journal of Information Management 15(1), 1-11. http://dx.doi.org/10.4102/sajim.v15i1.541

Cisco, 2009, 'Cloud computing in higher education: A guide to evaluation and adoption', Cisco White Paper, SanJose.

Comninos, A., 2011, 'Southern African Internet Governance Forum Issue Papers', SANGONeT for the Southern African Internet Governance Forum, 1-3 September 2011, Johannesburg, South Africa.
Technology Organization Environmental framework

Technology; Environment

Organisation; Environment

Organisation

Organisation; Technology

Technology; Environment

Duhaime, D., 2011, 'The pros and cons of cloud computing', ExpectFocus ${ }^{\circledR}$ III, Summer.

Fichman, R.G., Kohli, R., Krishnan R. \& Kane, K.C., 2011, 'Editorial overview-the role of information systems in healthcare: Current research and future trends', Information Systems Research 22(3), 419-428. http://dx.doi.org/10.1287/ Information Syste

Gonçalves, V. \& Ballon, P., 2011, 'Adding value to the network: Mobile operators' experiments with software-as-a-service and platform-as-a-service models', Telematics and Informatics 28, 12-21. http://dx.doi.org/10.1016/j.tele.2010. 05.005

Hsieh, J.C. \& Hsu, M.W., 2012, 'A cloud computing based 12-lead ECG telemedicine service', BMC Medical Informatics and Decision Making 12(1), 77-89. http://dx.doi.org/10.1186/1472-6947-12-77

IRIN, 2008, 'South Africa wanted -4,000 doctors', viewed 05 January 2013, from http:// www.plusnews.org/Report/79241/SOUTH-AFRICA-WANTED-4-000-doctors

ISACA, 2009, 'Cloud Computing: Business Benefits With Security, Governance and Assurance Perspectives', An ISACA Emerging Technology White Paper, Rolling Meadows.

ISO, 2013, 'Technical Committee 215: Health informatics', viewed 05 January 2014, from http://www.iso.org/iso/iso_technical_committee?commid $=54960$

Jack, C. \& Mars, M., 2008, 'Telemedicine a need for ethical and legal guidelines in South Africa', South African Family Practice 50, 60-61. http://dx.doi.org/10.1080 /20786204.2008.10873698

Jacobs, F., 2007, ' 185 - The patients per doctor map of the world', viewed 05 January 2013, from http://bigthink.com/strange-maps/185-the-patients-per-doctor-mapof-the-world

Koch, A. \& Van Brakel, P., 2012, 'Why health organizations should make use of the Cloud instead of traditional Information and Communication Technologies (ICTs)', Proceedings of the 14th annual conference on World Wide Web Applications, 7-9 November, Cape Town, South Africa.

Lohr, H., Sadeghi, A.R. \& Winandy, M., 2010, 'Securing the e-health cloud', Proceedings of the 1st ACM International Health Informatics Symposium, 11-12 November, Arlington, United States of America, pp. 220-229.

Low, C., Chen, Y. \& Wu, M., 2011, 'Understanding the determinants of cloud computing adoption', Industrial Management \& Data Systems 111(7), 1006-1023. http://dx.doi.org/10.1108/02635571111161262

Madhavaiah, C., Bashir, I. \& Shafi, S.I., 2012, 'Defining cloud computing in business perspective: A review of Research', SAGE 163-173. http://dx.doi. org/10.1177/0972262912460153

Malhotra, N.K., 2010, 'Review of cloud research marketing', in N. K. Malhotra (ed.) Review of cloud research marketing, vol. 7, pp. 85-96, Emerald Group Publishing Limited, Bingley.

Mars, M., 2012, 'Telepsychiatry in Africa - a way forward?', African Journal of Psychiatry 15, 215-217. http://dx.doi.org/10.4314/ajpsy.v15i4.27

Mars, M., 2013, 'Telemedicine and advances in urban and rural healthcare delivery in Africa', Progress in cardiovascular diseases 56(3), 326-335. http://dx.doi. org/10.1016/j.pcad.2013.10.006

Mauch, V., Kunze, M. \& Hillenbrand, M., 2012, 'High performance cloud computing', Future Generation Computing Systems 59(6), 1408-1416.

Melvin, F. \& Pranesh, R., 2013, 'Independent medical care unit for rrual health care development', International Journal of New Trends in Electronics and Communication 1(1), 15-18.

Motsoaledi, M., 2010, 'Speaking notes for Dr. A.P Motsoaledi', 1st Southern African Telemedicine Conference Keynote address, viewed 22 February 2013, from http://www.doh.gov.za/show.php?id=2104

Nwabueze, S.N., Meso, N.P., Kifle, N., Okoli, C. \& Chustz, M., 2009, 'The effects of culture of adoption of Telemedicine in medically underserved communities', in Proceedings of the 42nd Hawaii International Conference on System Sciences, Hawaii, United States of America, pp. 1-10.

Oliveira, T. \& Martins, M.F., 2011, 'Literature review of information technology adoption models at firm level', The Electronic Journal Information Systems Evaluation 14(1), 110-121.

Ragent, F. \& Leach, C., 2010, 'Can you trust the cloud?', A Practical Guide to the Opportunities and Challenges Involved in Cloud Computing, Cloud Computing, viewed 04 September 2014, from http://www.xerox.com/thoughtleadership

Rolim, C., Koch, F., Westphall, C., Werner, J., Fracalossi, A. \& Salvador, G.A., 2010, 'Cloud computing solutions for patient's data collection in health care institutions', $2 n d$ International Conference on Health, Telemedicine, and Social Medicine, pp. 95-99.

Rosado, D.G., Gomez, R., Mellado, D. \& Fernandez-Medina, E., 2012, 'Security analysis in the migration to cloud environments', Future Internet 4(2), 469-487.

Salaheldin, S.I., 2009, 'Critical success factors for TQM implementation and their impact on performance of SMEs', International Journal of Productivity and Performance Management 58(3), 215-237. http://dx.doi.org/10.1108/17410400910938832

Schwab, K., 2010, 'The Global Competitiveness Report', World Economic Forum, Geneva, Switzerland. 
Singh, V., 2009, 'Telemedicine and mobile telemedicine system', viewed 02 February 2013, from http://www.works.bepress.com/vikas_singh

Teng, CC., Mitchell, J., Walker, C., Swan, A., Davila, C. et al., 2010, 'A medical image archive solution in the cloud', in Software Engineering and Service Sciences (ICSESS), 2010 IEEE International Conference.

Truong, H.L., Pham, V.T., Thoai, N. \& Dustdar, S., 2012, 'Cloud computing for education and research in developing countries', in L. Chao (ed.), Cloud computing for teaching and learning: Strategies for design and implementation, pp. 64-80, Information Science Reference, Hershey.
Van Dyk, L., Fortuin, J. \& Schutte, C., 2012, 'Maturity model for telemedicine implementation', Proceedings of the eTELEMED 2012: The Fourth International Conference on eHealth, Telemedicine, and Social Medicine, 30 January - 04 February, Valencia, Spain, pp. 69-71.

WHO, 2011 'What is eHealth: The World Health Organisation (WHO) definition', viewed 06 January, 2013 from http://www.ehealthexpert.org/defehealth

Wootton, R., Patil, N.G., Scott, R.E. \& Ho, K., 2009, 'Telemedicine offers solutions for Telehealth in the Developing World', Royal Society of Medicine Press, London. 